\title{
BRCA1 and BRCA2 genetic test in high risk patients and families: Counselling and management
}

\author{
ELEONORA MARCHINA $^{1 *}$, MARIA GRAZIA FONTANA ${ }^{2 *}$, MICHELA SPEZIANI $^{3}$, \\ ALESSANDRO SALVI ${ }^{1}$, GIUSEPPE RICCA ${ }^{4}$, DIEGO DI LORENZO ${ }^{5}$, MARIA GERVASI ${ }^{5}$, \\ LUIGI CAIMI $^{5}$ and SERGIO BARLATI ${ }^{1}$ \\ ${ }^{1}$ Division of Biology and Genetics, Department of Biomedical Sciences and Biotechnology, and \\ ${ }^{2}$ First Division of General Surgery, Department of Medical and Surgical Sciences, University of Brescia, Brescia; \\ ${ }^{3}$ Ambulatori Oncologici Raphael, Cooperativa Sociale O.N.L.U.S., Calcinato, Brescia; ${ }^{4}$ Servizi Sociali A.O. Spedali Civili, \\ Brescia; ${ }^{5}$ Laboratory of Biotechnology, Department of Laboratory Medicine, Civic Hospital of Brescia, Brescia, Italy
}

Received June 25, 2010; Accepted August 20, 2010

DOI: 10.3892/or_00001031

\begin{abstract}
Hereditary breast cancer accounts for 5-10\% of all cases of breast cancer and $10-15 \%$ of ovarian cancer and is characterised by dominant inheritance, early onset, the severity of the disease and bilaterality. About $30 \%$ of cases with hereditary breast and ovarian cancer have mutations in the BRCA1 and BRCA2 genes. Women with a mutation in the BRCA1 gene have a $80-90 \%$ lifetime risk of developing breast cancer, and 40-65\% chance of developing ovarian cancer. Most studies carried out throughout the world indicate that the prevalence of BRCA1 and BRCA2 mutation is lower than originally suggested by early studies on large families with several affected members. Studies performed in Italy have reported different prevalence of BRCA1 and BRCA2 mutations, probably due to different selection criteria and to the variability of the techniques used. In this study, we performed a screening of BRCA1 and BRCA2 in families from northern Italy with familial recurrence of breast cancer or ovarian cancer in which the individual risk of patients of being carriers of BRCA1 and BRCA2 mutation was evaluated using BRCAPRO (CAGene) software. We enrolled 27 patients of 101 unrelated families selected when they fulfilled the inclusion criteria of the American Society of Clinical Oncology (ASCO). Specific risk evaluation, genetic test administration if needed, and discussion of the results were offered during multi-
\end{abstract}

Correspondence to: Dr Eleonora Marchina, Division of Biology and Genetics, Department of Biomedical Sciences and Biotechnology, University of Brescia, Viale Europa 11, 25123 Brescia, Italy

E-mail: marchina@med.unibs.it

${ }^{*}$ Contributed equally

Key words: BRCA1-2 mutations, hereditary breast and ovarian cancer disciplinary genetic, surgical and psychological counselling. Seven probands (35\%) found BRCA1/2 sequence variation carriers; no BRCA1 and BRCA2 mutations were detected in the remaining 13 probands. Two (15\%) patients had BRCA1 mutations and $5(25 \%)$ patients had BRCA2 mutations. In the latter case, BRCA2 delA 9158fs+29stop mutation in exon 22, never previously described and a new sequence variation $(\mathrm{T} 703 \mathrm{~N})$ in exon 11 were identified.

\section{Introduction}

Breast cancer is the most common malignancy in women in the Western world $(1,2)$. Hereditary breast cancer accounts for $5-10 \%$ of all cases of breast cancer and $10-15 \%$ of ovarian cancer and is characterised by dominant inheritance, early onset, severity of the disease and bilaterality (3).

Linkage analysis in large kindreds with hereditary breast cancer has identified two genes, BRCA1 (17q21, OMIM $113705)$ and BRCA2 (13q14, OMIM 600185), whose mutations cause a high lifetime risk of breast cancer and ovarian cancer $(4,5)$.

Some (approximately 30\% of cases) individuals with hereditary breast and ovarian cancer have mutations in the BRCA1 and BRCA2 genes $(6,7)$. Some authors have reported that germline mutations in the breast and ovarian cancer susceptibility genes BRCA1 and BRCA2, confer a high risk of developing breast and ovarian cancer. Women with a mutation in the BRCA1 gene have a $80-90 \%$ lifetime risk of developing breast cancer and 40-65\% chance of developing ovarian cancer. For BRCA2 gene mutation carrier, the estimated cumulative risk of breast cancer is $28 \%$ by the age of 50 and $84 \%$ by the age of 70 . The risk of ovarian cancer is $0.4 \%$ by the age of 50 and $27 \%$ by the age of 70 years (8-10).

Risk factors include personal/family history of early onset breast cancer, ovarian cancer, multiple family members with breast/ovarian cancer, male breast cancer, multiple primary breast/ovarian cancers in one individual and Ashkenazi Jewish ancestry (11). Most studies carried out 
throughout the world indicate that the prevalence of BRCA1 and BRCA2 mutation is lower than originally suggested by early studies on large families with several affected members $(8,12,13)$.

In providing genetic counselling to individuals at risk of BRCA1 and BRCA2 mutations, tools have been developed to aid in providing risk assessment. These include BRCAPRO, Myriad II, BOADICEA, UPenn, and UPennII, among others. Although it varies between institutions, BRCAPRO is commonly used in clinical practice and is the primary tool used in the present study. The BRCAPRO Bayesian probability model [accessed through CancerGene (http:// www3.utsouthwestern.edu/cancergene/)] is a computerbased program that predicts the likelihood of identifying a BRCA1 and BRCA2 mutation, given family history. This model was developed using mutation rates of Ashkenazi Jewish and other European populations (14-19).

Nanda et al (20), reported that BRCAPRO was as sensitive for African Americans as it was for Ashkenazi and European controls. Studies performed in Italy reported different prevalence of BRCA1 and BRCA2 mutations, probably due to the different selection criteria and to the variability of the techniques used $(12,13,21,22)$.

It is essential to identify and provide genetic counselling for women who are at high risk, in order to assess the individual disease risk, calculate the probability of mutationcarrier status, offer genetic analysis, advise women on the need for an intensified early detection on cancer, provide preventive care and prophylactic surgery and offer psychological support $(23,24)$.

Rapid advances in susceptibility genetic testing for hereditary breast cancer have modified clinical practice. Large epidemiology studies of gene carriers have been conducted to identify potential risk modifiers. Depending on her level of risk, a women may opt for intensive followup with magnetic resonance (25-28) or for prophylactic surgery $(29,30)$.

In this study, we screened BRCA1 and BRCA2 in families from northern Italy with familial recurrence of breast cancer or ovarian cancer in which the individual risk of patients to be carriers of BRCA1 and BRCA2 mutation was evaluated using BRCAPRO (CAGene) software.

We enrolled 27 patients of 101 unrelated families selected for this analysis when they fulfilled the inclusion criteria by the American Society of Clinical Oncology (ASCO) (8).

Seven probands $(35 \%)$ found BRCA $1 / 2$ sequence variation carriers; no BRCA1 and BRCA2 mutations were detected in the remaining 13 probands. Two (15\%) patients had BRCA1 mutations and $5(25 \%)$ patients had BRCA2 mutations. In the latter case, BRCA2 delA 9158fs+29stop mutation in exon 22 , never previously described and a new sequence variation $(\mathrm{T} 703 \mathrm{~N})$ in exon 11 was identified.

\section{Materials and methods}

Patients. DNA from 20 patients from 20 different families were screened for BRCA1 and BRCA2 mutations. In all cases, DNA was collected with their informed consent and the study was approved by the Local Ethics Committee.
101

(PATIENTS WITH BC AND/OR FAMILIAL HISTORY EVALUATED) SELECTION CRITERIA (BrCaPRO)

27

(ENROLLED PATIENTS)

(BRCA1/2 MUTATION ANALYSIS TESTS)

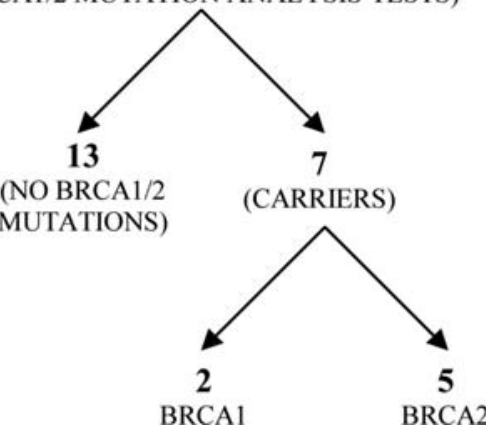

Figure 1. The flow chart outlines the steps from patients recruiting to genetic tests providing genetic counselling.

Table I. BRCA1 sequence variations detected in this study.

\begin{tabular}{lllc}
\hline Exon/intron & Variant & Effect & No. of patients \\
\hline Intron 1 & $134 \mathrm{~T} \rightarrow \mathrm{C}$ & $\mathrm{P}^{\mathrm{a}}$ & 8 \\
Exon 5 & $\mathrm{C64R}$ & $\mathbf{M}^{\mathrm{a}}$ & $\mathbf{2}$ \\
Intron 7 & $-34 \mathrm{C} \rightarrow \mathrm{T}$ & $\mathrm{P}$ & 5 \\
Intron 8 & -58 delT & $\mathrm{P}$ & 8 \\
Exon 9 & $\mathrm{C} 197 \mathrm{C}$ & $\mathrm{P}$ & 2 \\
Exon 11 & $\mathrm{Q} 356 \mathrm{R}$ & $\mathrm{P}$ & 2 \\
Exon 11 & $\mathrm{D} 693 \mathrm{~N}$ & $\mathrm{P}$ & 1 \\
Exon 11 & $\mathrm{S} 694 \mathrm{~S}$ & $\mathrm{~S}$ & 11 \\
Exon 11 & $\mathrm{L} 771 \mathrm{~L}$ & $\mathrm{~S}$ & 11 \\
Exon 11 & $\mathrm{P} 871 \mathrm{~L}$ & $\mathrm{P}$ & 11 \\
Exon 11 & $\mathrm{E} 1038 \mathrm{G}$ & $\mathrm{P}$ & 11 \\
Exon 11 & $\mathrm{K} 1183 \mathrm{R}$ & $\mathrm{P}$ & 11 \\
Exon 13 & $\mathrm{S} 1436 \mathrm{~S}$ & $\mathrm{~S}$ & 7 \\
Exon 16 & $\mathrm{S} 1613 \mathrm{G}$ & $\mathrm{P}$ & 3 \\
Intron 14 & $-63 \mathrm{C} \rightarrow \mathrm{G}$ & $\mathrm{P}$ & 7 \\
Exon 16 & $\mathrm{M} 1652 \mathrm{I}$ & $\mathrm{P}$ & 1 \\
Intron 16 & $-68 \mathrm{~A} \rightarrow \mathrm{G}$ & $\mathrm{P}$ & 7 \\
Intron 16 & $-92 \mathrm{~A} \rightarrow \mathrm{G}$ & $\mathrm{P}$ & 7 \\
Intron 17 & $+66 \mathrm{G} \rightarrow \mathrm{A}$ & $\mathrm{P}$ & 4 \\
Intron 18 & $+66 \mathrm{G} \rightarrow \mathrm{A}$ & $\mathrm{P}$ & 8 \\
\hline
\end{tabular}

${ }^{\text {ap}}$, polymorphism; M, mutation; $\mathrm{S}$, synonimous .

Biological samples. Genomic DNA was extracted from $200 \mu \mathrm{l}$ of EDTA-anti-coagulated blood with use of the QIAamp 
Table II. BRCA2 sequence variations detected in this study.

\begin{tabular}{|c|c|c|c|}
\hline Exon/intron & Variant & Effect & No. of patients \\
\hline Intron 1 & $-27 \mathrm{G} \rightarrow \mathrm{A}$ & $\mathrm{P}^{\mathrm{a}}$ & 5 \\
\hline Exon 2 & $203 \mathrm{G} \rightarrow \mathrm{A} 5^{\prime} \mathrm{UTR}$ & $\mathrm{P}$ & 3 \\
\hline Intron 4 & $+66 \mathrm{~A} \rightarrow \mathrm{C}$ & $\mathrm{P}$ & 1 \\
\hline Intron 4 & $-90 \mathrm{~T} \rightarrow \mathrm{C}$ & $\mathrm{P}$ & 1 \\
\hline Intron 8 & $909+56 \mathrm{C} \rightarrow \mathrm{T}$ & $\mathrm{P}$ & 1 \\
\hline exon 10 & $\mathrm{~N} 372 \mathrm{H}$ & $\mathrm{P}$ & 7 \\
\hline Exon 10 & $\mathrm{~N} 289 \mathrm{H}$ & $\mathrm{P}$ & 1 \\
\hline Exon 10 & 458 stop & $\mathbf{M}^{\mathbf{a}}$ & 1 \\
\hline Intron 10 & $-74 \mathrm{~T} \rightarrow \mathrm{C}$ & $\mathrm{P}$ & 3 \\
\hline Exon 11 & T703N & $\begin{array}{c}\text { Novel } \\
\text { variation }\end{array}$ & 2 \\
\hline Exon 11 & V1270V & $\mathrm{S}^{\mathrm{a}}$ & 4 \\
\hline Exon 11 & K1132K & $S$ & 9 \\
\hline Exon 11 & $\mathrm{~T} 1915 \mathrm{M}$ & $\mathrm{P}$ & 1 \\
\hline Exon 11 & $\mathrm{H} 723 \mathrm{H}$ & $\mathrm{S}$ & 1 \\
\hline Intron 14 & $+53 \mathrm{C} \rightarrow \mathrm{T}$ & $\mathrm{P}$ & 1 \\
\hline Exon 14 & S2414S & $S$ & 8 \\
\hline Intron 16 & $-14 \mathrm{C} \rightarrow \mathrm{T}$ & $\mathrm{P}$ & 8 \\
\hline Intron 16 & $-15 \mathrm{C} \rightarrow \mathrm{T}$ & $\mathrm{P}$ & 1 \\
\hline Intron 21 & $-66 \mathrm{~T} \rightarrow \mathrm{C}$ & $\mathrm{P}$ & 9 \\
\hline Exon 22 & Q2960stop & $\mathbf{M}$ & 1 \\
\hline Exon 22 & del A 9158 fs+29Stop & $\mathbf{M}$ & 1 \\
\hline Intron 22 & $+99 \mathrm{~T} \rightarrow \mathrm{C}$ & $\mathrm{P}$ & 1 \\
\hline Exon 27 & $10590 \mathrm{~A} \rightarrow \mathrm{C} 3^{\prime} \mathrm{UTR}$ & $\mathrm{P}$ & 3 \\
\hline Exon 27 & $10854 \mathrm{~A} \rightarrow \mathrm{G}$ seq Alu & $\mathrm{P}$ & 3 \\
\hline Exon 27 & $10482+108 \mathrm{~A} \rightarrow \mathrm{C} 3^{\prime} \mathrm{UTR}$ & $\mathrm{P}$ & 1 \\
\hline
\end{tabular}

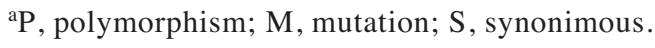

DNA Blood Mini Kit and according to the manufacturer's instructions (Qiagen). Primers for PCR amplifications were obtained from MWG Biotech. PCR reactions were carried out in a $50-\mu 1$ volume with $100 \mathrm{ng}$ of template genomic DNA, $200 \mu \mathrm{M}$ each of the deoxynucleotide triphosphates, $10 \mathrm{mM}$ Tris- $\mathrm{HCl}$ (pH 8.3), $50 \mathrm{mM} \mathrm{Kcl}, 2 \mathrm{mM} \mathrm{MgCl} 2,1.5 \mathrm{U}$ of AmpliTaq Gold (Applied Biosystems), and $25 \mathrm{pmol}$ of each primer.

DHPLC analysis and sequence. All encoded exons and intron-exon boundaries together with 5' and 3' UTR of BRCA1 and BRCA2 genes were analysed.

Mutation analysis was performed according to a previously described method (31-33) on a Transgenomic WAVE System equipped with a preheated C18 reversedphase column based on non-porous poly(styrene/divinylbenzene) particles (DNASep ${ }^{\mathrm{TM}}$; Transgenomics). The melting characteristics of the DNA fragments were predicted by using Wavemaker ${ }^{\mathrm{TM}}$ software. Direct sequencing confirmed the findings from the dHPLC analysis. Variants with altered elution profiles in dHPLC were sequenced directly in both directions with the appropriate primers.

\section{Results}

Between October 2006-October 2007, 101 patients underwent genetic counselling at the Breast Cancer Unit of the Spedali Civili of Brescia University. Eighty-nine patients had positive familial breast and ovarian cancer history; 6 were young women $(<40$ years old) with monolateral breast or ovarian cancers; 3 women had bilateral breast cancer and 3 patients were males. The cases included 98 Italian females and 3 Italian males; the mean age of the probands was 52.2 years for the females and 49 years for the males ranging between 24 and 86 years. The first step was determining the potential risk of being a BRCA1/2 mutation carrier using the BRCAPRO programme. Only patients with a score $\geq 10 \%$ were eligible for the genetic tests; a total of 27/101 (26.73\%) patients. Of these, 20 patients, 19 female and 1 male, accepted the mutational screening analysis of BRCA1/2 genes. Thirteen patients $(65 \%)$ did not have any mutations in BRCA1/2 genes and 7 (35\%) were carriers of germ line mutations in BRCA1/2. Two (10\%) patients had BRCA1 mutations and $5(25 \%)$ patients had BRCA2 mutations (Fig. 1). As shown in Tables I and II, the BRCA1 mutation 


\section{PATIENT 10}

$\mathbf{A}$

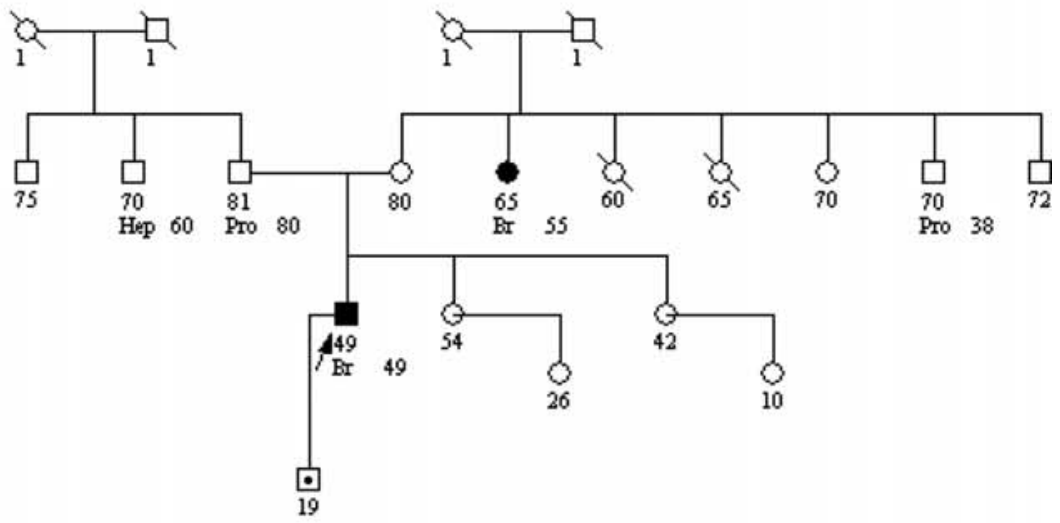

B

\section{PATIENT 17}

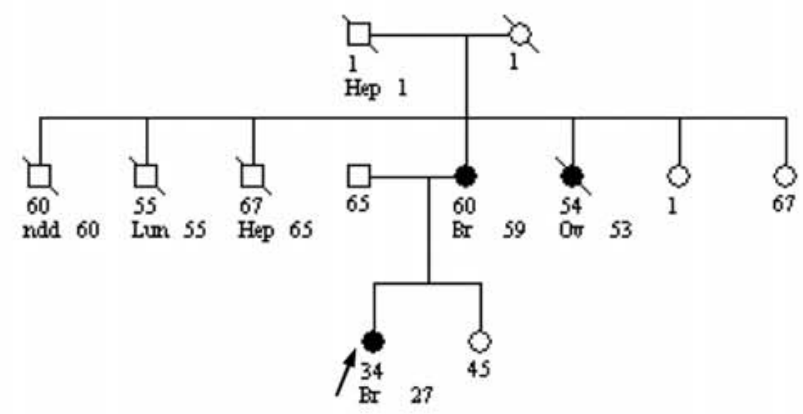

C

PATIENT 4

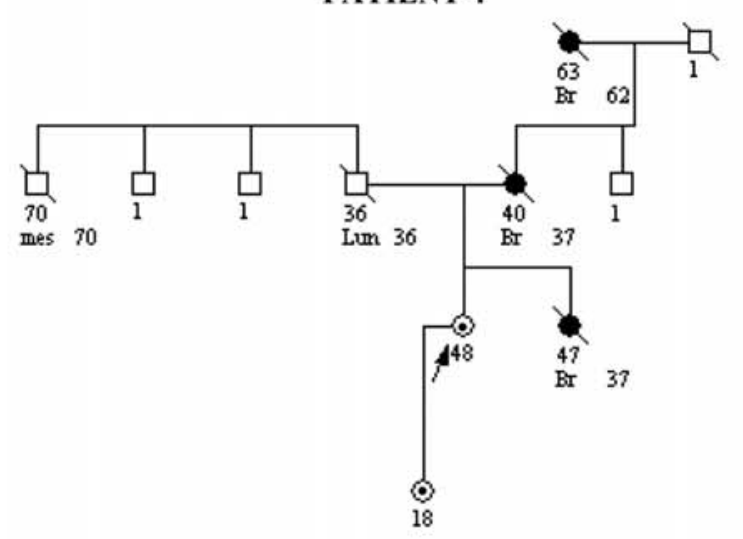

D

\section{PATIENT 14}

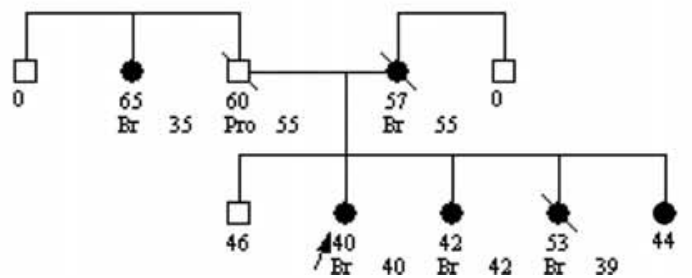

Figure 2. Pedigrees of patients with positive test. Arrow indicates the proband, point into empty symbol indicates unaffected carrier, full symbol affected subject.

C64R in exon 5 was found in 2 unrelated patients: a 39-yearold unaffected woman with a strong history of cancer and a 34-year-old patient (patient 17) with monolateral breast cancer diagnosed at the age of 27 and with strong family history for breast, ovarian, and brain cancer, and hepatocellular carcinoma (Fig. 2B). The BRCA2 458 stop mutation in the exon 10 was found in an asymptomatic 48-year-old woman (patient 4). This patient was addressed to genetic 
counselling because of the high incidence of breast cancer in her family. The BRCA2 sequence analysis was extended to the daughter of patient 4 . This asymptomatic 18-year-old woman was a carrier of the same mutation as detected in her mother. The nephew (the son of the dead sister of patient 4) did not have any mutations (Fig. 2C).

The BRCA2 Q2960stop mutation in exon 22 was present in a woman with breast cancer diagnosed at the age of 42 with positive cancer family history for breast, prostate and lung cancers. A 49-year-old male (patient 10, died at the age of 51) affected by breast cancer and with family history for prostate cancer and hepatocarcinoma had the BRCA2 delA $9158 \mathrm{fs}+29$ stop mutation in the exon 22 , never previously described (Fig. 2A). A new sequence variation (T703N) in exon 11 of BRCA2 gene was identified in two unrelated women. This was in an amino acid change in position 703 from threonine $(\mathrm{T})$ to asparagine $(\mathrm{N})$. The bio-computer tool Polyphen predicted that such an amino acid substitution could not alter the structure and function of the BRCA2 protein. This new variation was found in a 40-year-old female (patient 14) with breast cancer and with positive family history (Fig. 2D). The same sequence variation was also detected in an unaffected 56-year-old woman with a family history of cancer (her mother and grandmother died from ovarian cancer). Finally, several polymorphisms previously described and not considered pathogenetic were found both in BRCA1 and BRCA2 genes (Tables I and II). The BRCA1/2 genetic test analysis was proposed, after extensive genetic counselling to the high risk family members of probands no. 10, 17, 4 and 14 (Fig. 2).

Here, we briefly describe the results obtained. The son of patient 10 (19 years old, asymptomatic) was a carrier of the BRCA2 delA 9158fs+29stop mutation, detected in his father; patient 10 's sisters (54 and 42 years old, unaffected) did not have the mutation (Fig. 2A). The mother of patient 17 (60 years old) with breast cancer diagnosed at the age of 59 had the same BRCA2 C64R mutation detected in her daughter; while patient 17's sister (45 years old; unaffected) did not have the mutation (Fig. 2B). Patient 4's sister (died at the age of 47 , from breast cancer diagnosed at the age of 37) and her daughter (18 years old) had the same BRCA2 458stop mutation (Fig. 2C). Patient 14's sister (44 years old) with breast cancer did not have the BRCA2 mutation. Another sister affected by breast cancer (42 years old) (Fig. 2D) was also negative.

The unaffected mutation carriers identified after the extension of the BRCA1/2 mutational screening test to the proband's family members are now being monitored periodically to give adequate clinical surveillance.

\section{Discussion}

Recently, several reports have been carried out on hereditary breast and ovarian cancer, especially after identification of BRCA1 and BRCA2 genes. Several authors have identified $(12,13,21,34)$ mutations in BRCA1 and 2 genes in Italian populations and many others have reported prevention options to reduce risk.

Molecular analysis of BRCA1 and BRCA2 in various populations have shown a very large mutational spectrum and a variable mutation prevalence related to the different techniques used, to the criteria of selection and to the ethnic origins of patients $(20,35)$.

In this study, 20 Italian probands from 101 selected unrelated Italian families with history of breast or ovarian were enrolled for mutational analysis screening of BRCA1/ BRCA2 genes: 16 probands had high familial risk of breast and ovarian cancer; 2 probands had bilateral breast cancer and 2 patients were males with breast cancer. Our selection criteria based on the software BRCAPRO considered those probands which had a probability of being a carrier $>10 \%$ as being recruitable for the genetic test. Specific risk evaluation, genetic test administration if needed and discussion of the results were offered during multidisciplinary genetic, surgical and psychological counselling.

Seven probands $(35 \%)$ showed BRCA $1 / 2$ sequence variation carriers; no BRCA1 and BRCA2 mutations were detected in the remaining 13 probands. Two mutations were found in BRCA1 gene and 4 sequence variations were detected in BRCA2 gene (three mutations and one not previously described sequence variation found in two different patients). In the three previous screening studies carried out in Italy, on the entire BRCA1/BRCA2 sequences, Stuppia et al (21) detected mutations in $11.7 \%$ of 128 related Italian patients (68 Italian families), Ottini et al (13) detected mutations in $8 \%$ of 136 Italian patients, while Santarosa et al (12) found mutations in $37 \%$ of cases from 57 selected Italian families. These different detection rates were clearly due to the different selection criteria used, since Santarosa et al (12) used more stringent criteria of autosomal-dominant predisposition. The carrier percentage $(35 \%)$ found here was similar to Santarosa et al (37\%) and was higher to those found in the other two Italian studies based on unselected Italian patients $(21,13)$. Our results confirm the importance of using BRCAPRO software in selecting probands for subsequent genetic test (15). BRCAPRO uses information on male and female relatives, unilateral/bilateral breast cancer, and ovarian cancer cases in the family to give a percentage risk of being a carrier. The model also incorporates published gene frequencies and data on BRCA1 and BRCA2 penetrance.

Our data indicate that the detection rate of BRCA1/ BRCA2 mutations in our families with $\mathrm{BC}$ or $\mathrm{OC}$ from the central Italy is $35 \%$, confirming that, in clinical practice, most families attending genetic counselling for hereditary $\mathrm{BC}$ have a low risk of BRCA1/BRCA2 mutations (8).

In our case study, we found one male patient affected by breast cancer with the BRCA2 mutation. Male breast cancer accounts for less than $1 \%$ of all cancer in men. Evidence from several studies implicate pathogenetic BRCA2 germ line mutations and, with less often, BRCA1 in male breast cancer. Indeed, mutation frequencies ranged from $4-40 \%$ for BRCA2 and up to $4 \%$ for BRCA1 (36). Ottini et al (37) reported that constitutional BRCA1 and BRCA2 mutations accounted for $16 \%$ of male breast cancer.

It is relevant therefore, to consider that in $13 / 20(65 \%)$ probands there were no BRCA1/2 mutations. In this study, we used DHPLC to identify BRCA1/2 point mutations, small deletions and insertions. It is known that this technique does not detect genomic rearrangement (gene duplications, large deletions) found in $12-15 \%$ of the patients who are negative 
to DHPLC analysis. Furthermore, we can not exclude the presence of mutations in other susceptibility genes $(38,39)$. Thus, the diagnostic iter followed during management of patients/probands recruiting in our breast cancer unit was: i) selection of high risk probands using BRCAPRO software $(\mathrm{p}>10 \%)$; ii) administration of the genetic test to look for BRCA1/2 mutations in the patients enrolled; iii) If the genetic test was negative: a) further investigation (MLPA assay to search for eventual genomic rearrangements); b) p53 sequencing in patients with familial cancers associated with the Li-Fraumeni syndrome. In our case study, considering positive familial history for different types of cancer (ovarian, thyroid, kidney cancer, osteosarcoma), patient 17 (Fig. 2) might be candidate for p53 mutational analysis test (in progress); iv) in the case of positive tests, during genetic counselling, drugs treatment and surgical options are presented and described to the patient together with adequate clinical and radiological surveillance; v) evaluation of genetic test results using Polyphen and/or HGMD to predict the impact of an eventual new variation on the BRCA $1 / 2$ protein or to verify whether a variation has already been described.

To our knowledge, the sequence variation T703N (Table II) found in our study, has not been described before. As mentioned in Results, the Polyphen predicted that such amino acid substitution would not alter the function of BRCA2 protein. This, together with the fact that the 2 sisters of patient 14 with breast cancer were not carriers of the sequence variation, and with the identification of this variation in an unaffected 56-year-old women with ovarian cancer family history, could suggest that T703N may be a new SNP. Nevertheless, we believe it would be useful to carry out future case-control studies to find the role of T703N sequence variations. The other new variation delA $9158 \mathrm{fs}+29$ stop found here, is clearly a pathogenetic mutation since it causes BRCA2 protein premature truncation.

According to international guidelines for genetic tests, we chose to offer the genetic testing first to the affected individual and afterwards extended it to unaffected family members at risk. BRCA2 mutation analysis extended to some proband family members, allowed us to identify mutation carriers. For example (Fig. 2), patient 10's son (19 years old) and patient 4's daughter (18 years old) were carriers of the delA 9158 fs+29stop new mutation and BRCA2 458stop mutation, respectively. They have now been informed about their predisposition and the risks of developing breast/ovarian cancers and adequate surveillance is ongoing.

The effectiveness of surveillance in high-risk women and especially BRCA1/2 mutation carriers is unknown. Our surveillance includes: i) breast self examination (monthly), starting at the age of 18 ; ii) breast clinical control twice a year in association with ultrasounds starting at the age of 25 ; iii) annual mammograms and/or magnetic resonance (MR) from the age of 25 or individualized according to the earliest onset age in the family; iv) trans-vaginal ultrasound and CA125 measurement twice a year. Surgical prevention includes: i) prophylactic mastectomy that offers the greatest reduction in breast cancer risk $(95 \%)(29,30)$; ii) prophylactic oophorectomy before the age of 40 is associated with a $50 \%$ reduction in the risk of breast cancer and $80 \%$ reduction risk of ovarian and peritoneal cancer (41).

Chemoprevention with Tamoxifen has been shown to reduce the risk of breast cancer by $50 \%$ in women at high risk. In addition, Tamoxifen has been shown to prevent contra-lateral breast cancer in women with a BRCA1 or BRCA2 mutation (30).

In conclusion, we believe that the diagnostic iter guidelines and the management of our patients could be fundamental in identifying individuals at high risk of breast cancer development and to apply adequate surveillance protocols in the early stage of the pathology (or prior) with subsequent increased survival and improved quality of life.

\section{References}

1. Parkin DM, Berry D and Aguila O: Global Cancer Statistic, 2002. CA Cancer J Clin 55: 74-108, 2005.

2. Jemal A, Siepel R, Ward E, Murray T, Xu J and Thun MJ: Cancer statistic, 2007. CA Cancer J Clin 57: 43-66, 2007.

3. Claus EB, Risch N and Thompson WD: Autosomal dominant inheritance of early-onset breast cancer: implication for risk prediction. Cancer 73: 643-651, 1994.

4. Miki Y, Swensen J, Shattuck-Eidens D, et al: A strong candidate for the breast and ovarian cancer susceptibility gene BRCA1. Science 266: 66-71, 1994.

5. Wooster R, Bignelli G, Lancaster J, et al: Identification of the breast cancer susceptibility gene BRCA2. Nature 378: 789-792, 1995.

6. Antoniou AC and Easton DF: Models of genetic susceptibility to breast cancer. Oncogene 25: 5898-5905, 2006.

7. Bradbury AR and Olopade OI: Genetic susceptibility to breast cancer. Rev Endocr Metab Disord 8: 255-267, 2007.

8. Ford D, Easton DF, Bishop DT, Narod SA and Goldgar DE: Risk of cancer in BRCA1-mutation carriers. Breast Cancer Linkage Consortium. Lancet 343: 692-695, 1994.

9. Narod S, Ford D, Devilee P, et al: Genetic heterogeneity of breast and ovarian cancer revisited. Breast Cancer Linkage Consortium. Am J Hum Genet 54: 957-958, 1995.

10. Rebbeck TR and Domchek SM: Variation in breast cancer risk in BRCA1 and BRCA2 mutation carrier. Breast Cancer Res 10: 108, 2008.

11. Shattuck-Eidens D, Oliphiant A, McClurer M, et al: BRCA1 sequence analysis in women at high risk for susceptibility mutations. Risk factor analysis and implications for genetic testing. JAMA 278: 1242-1250, 1997.

12. Santarosa M, Dolcetti R, Magri MD, et al: BRCA1 and BRCA2 genes: role in hereditary breast and ovarian cancer in Italy. Int J Cancer 83: 5-9, 1999.

13. Ottini L, D'Amico C, Noviello C, et al: BRCA1 and BRCA2 mutation in central and southern Italian patients. Breast Cancer Res 2: 307-310, 2000.

14. Parmigiani G, Berry D, Aguila O, et al: Determining carrier probabilities for breast cancer susceptibility gene BRCA1 and BRCA2. Am J Hum Genet 62: 145-158, 1998.

15. Berry DA, Iversen ES Jr, Gudbjartsson DF, et al: BRCAPRO validation, sensitivity of genetic testing of BRCA1/BRCA2, and prevalence of other breast cancer susceptibility genes. J Clin Oncol 20: 2701-2712, 2002.

16. Hoskins KF, Zwaagstra A and Ranz M: Validation of a tool for identifying women at high risk for hereditary breast cancer in population-based screening. Cancer 107: 1769-1776, 2006.

17. Capalbo C, Ricevuto E, Vestri A, et al: Improving the accuracy of BRCA1/2 mutation prediction: validation of the novel country customized IC software. Eur J Hum Genet 14: 49-54, 2006.

18. Ready KY, Vogel KJ, Atchley DP, et al: Accuracy of the BRCAPRO model among women with bilateral breast cancer. Cancer 115: 725-730, 2009.

19. Van Harssel JJ, Van Roozendaal CE, Detisch Y, et al: Efficiency of BRCAPRO and Myriad II mutation probability thresholds versus cancer history criteria alone BRCA $1 / 2$ mutation detection. Fam Cancer 9: 193-201, 2009. 
20. Nanda R, Schumm LP, Cummings S, et al: Genetic testing in an ethnically diverse cohort of high-risk women. JAMA 294 : 1925-1933, 2005.

21. Stuppia L, DiFulvio P, Aceto G, et al: BRCA1 and BRCA2 mutation in breast/ovarian cancer patients from central Italy. Hum Mutat 22: 178-179, 2003.

22. Montagna M, Della Palma M, Menin C, et al: Genomic rearrangements account for more than one-third of the BRCA1 mutation in northern Italian breast/ovarian cancer families. Hum Mol Genet 12: 1055-1061, 2004

23. Meiser B: Psychological impact of genetic testing for cancer susceptibility: an update of the literature. Psychooncology 14: 1060-1074, 2005

24. Tutt $\mathrm{A}$ and Ashworth A: Can genetic testing guide treatment in breast cancer? Eur J Cancer 44: 2774-2780, 2008.

25. Hadden WE: Recommendations for the surveillance of young women at increased risk for breast cancer. Australas Radiol 51: 1-11, 2007

26. Sardanelli F, Podo F, D'angelo G, et al: Multicenter comparative multimodality surveillance of women at genetic-familial high risk for breast cancer (HIBCRIT study): interim results. Radiology 242: 698-715, 2007.

27. Saslow D, Boetes C, Burke W, et al: American Cancer Society guidelines for breast screening with MRI as an adjunct to mammography. CA Cancer J Clin 57: 75-89, 2007.

28. Warner E, Messersmith H, Causer P, Eisen A, Shumak R and Plewes D: Systematic review: using magnetic resonance imaging screen women at high risk for breast cancer. Ann Intern Med 148: 671-679, 2008.

29. Hartmann LC, Schaid DJ, Woods JE, et al: Efficacy of bilateral prophylactic mastectomy in women with a family history of breast cancer. N Engl J Med 340: 77-84, 1999.

30. Metcalfe K, Lynch HT, Ghadirian P, et al: Controlateral breast cancer in BRCA1 and BRCA2 mutation carriers. J Clin Oncol 22: 2328-2335, 2004.
31. Gross E, Arnold N, Pfeifer K, Bandick K and Kiechle M: Identification of specific BRCA1 and BRCA2 variants by DHPLC. Hum Mutat 16: 345-353, 2000.

32. Xiao W and Oefner PJ: 1 Denaturing high-performance chromatography: a review. Hum Mutat 17: 439-474, 2001.

33. Cremonesi L, Sterrini S, Fermo I, et al: Denaturing HPLC analysis of DNA deletions and insertions. Hum Mutat 22: 98-102, 2003.

34. Capalbo C, Ricevuto E, Vestri, A et al: BRCA1 and BRCA2 genetic testing in Italian breast and/or ovarian cancer families: mutation spectrum and prevalence and analysis of mutation prediction models. Ann Oncol 17 (Suppl. 7): 34-40, 2006.

35. Fackenthal JD and Olopade OI: Breast cancer risk associated with BRCA1 and BRCA2 in diverse population. Nature 7: 937-948, 2007.

36. Fentiman IS, Fourquet A, Hortobagyi GN, et al: Male breast cancer. Lancet 367: 595-604, 2006.

37. Ottini L, Masala G, D'Amico C, et al: BRCA1 and BRCA2 mutation status and tumor characteristic in male breast cancer: a population-based study in Italy. Cancer Res 63: 342-347, 2003.

38. Walsh T, Casadei S, Coats KH, et al: Spectrum of mutation in BRCA1, BRCA2, CHEK2, and TP53 in families at high risk of breast cancer. JAMA 295: 13791-13388, 2006.

39. Veschi S, Aceto G, Scioletti AP, et al: High prevalence of BRCA1 deletion in BRCAPRO positive patients with high carrier probability. Ann Oncol 18 (Suppl. 6): 86-92, 2007.

40. Rebbeck TR, Friebel T, Lynch HT, et al: Bilateral prophylactic mastectomy reduces breast cancer risk in BRCA1 and BRCA2 mutation carriers: the PROSE Study Group. J Clin Oncol 22: 1055-1062, 2004

41. Rebbeck TR, Kauff ND and Domchek S: Meta-analysis of risk reduction estimates associated with risk reduction salpingooophorectomy in BRCA1 or BRCA2 mutation carriers. J Natl Cancer Inst 101: 80-87, 2009. 